\title{
Asymmetric Polyoxometalate Electrolytes for Advanced Redox Flow Batteries
}

Jochen Friedl,, ${ }^{\ddagger}$ a Matthäa V. Holland-Cunz, ${ }^{\ddagger, a}$ Faye Cording, ${ }^{a}$ Felix Pfanschilling, ${ }^{a}$ Corinne Wills, ${ }^{a}$ William McFarlane, ${ }^{a}$ Barbara Schricker, ${ }^{\text {b }}$ Robert Fleck, ${ }^{\text {b }}$ Holger Wolfschmidt ${ }^{\mathrm{b}}$ and Ulrich Stimming ${ }^{*, a}$

\footnotetext{
a. Chemistry -School of Natural and Environmental Sciences, Bedson Building, Newcastle University, Newcastle upon Tyne, NE1 7RU, United Kingdom b. Siemens AG, Corporate Technology, 91058 Erlangen, Germany

‡ These authors contributed equally.

* corresponding author: Ulrich.stimming@newcastle.ac.uk

Electronic Supplementary Information (ESI) available: Materials and methods, impedance spectroscopy of $\mathbf{S i W}_{\mathbf{1 2}}, \mathrm{pH}_{\text {stability of }} \mathbf{S i W}_{\mathbf{1 2}}$ and $\mathbf{P V}_{\mathbf{1 4}}$, membrane permeation of $\mathbf{S i W}_{\mathbf{1 2}}$, impedance spectroscopy of flow battery, post-cycling ${ }^{51} \mathrm{~V}$ NMR of $\mathbf{P V}_{\mathbf{1 4}}$, symmetric $\mathbf{P V}_{\mathbf{1 4}} \mathbf{V S}$. $\mathbf{P V}_{\mathbf{1 4}}$ flow battery. See DOI: $10.1039 / x 0 x \times 00000 x$
}

\begin{abstract}
Electrochemical storage of energy is a necessary asset for the integration of intermittent renewable energy sources such as wind and solar power into a complete energy scenario. Redox flow batteries (RFBs) are the only type of battery in which the energy content and the power output can be scaled independently, offering flexibility for applications such as load levelling. However, the prevailing technology, the all Vanadium system, comprises low energy and low power densities. In this study we investigate two polyoxometalates (POMs), $\left[\mathrm{SiW}_{12} \mathrm{O}_{40}\right]^{4-}$ and $\left[\mathrm{PV}_{14} \mathrm{O}_{42}\right]^{9-}$, as nano-sized electron shuttles. We show that these POMs exhibit fast redox kinetics (electron transfer constant $k_{0} \approx 10^{-2}$ $\mathrm{cm} \mathrm{s}^{-1}$ for $\left.\left[\mathrm{SiW}_{12} \mathrm{O}_{40}\right]^{4-}\right)$, thereby enabling high power densities; in addition, they feature multielectron transfer, realizing a high capacity per molecule; they do not cross cation exchange membranes, eliminating self-discharge through the separator; and they are chemically and electrochemically stable as shown by in-situ NMR. In flow battery studies the theoretical capacity (10.7 $\mathrm{Ah} \mathrm{L}^{-1}$ ) could be achieved under operating conditions. The cell was cycled for 14 days with current densities in the range of 30 to $60 \mathrm{~mA} \mathrm{~cm}^{-2}$ (155 cycles). The coulombic efficiency was $94 \%$ during cycling. Very small losses occurred due to residual oxygen in the system. The voltage efficiency $\left(\sim 65 \%\right.$ at $\left.30 \mathrm{~mA} \mathrm{~cm}^{-2}\right)$ was mainly affected by ohmic rather than kinetic losses. Pathways for further improvement are discussed.
\end{abstract}

\section{Broader context}

Using renewable energies such as solar and wind requires an energy management that contains energy storage capabilities. Redox flow batteries (RFBs) are an option that can be used in decentralised as well as in centralised systems. RFBs are the only type of battery in which the energy content and the power output can be scaled independently, offering a high flexibility for applications such as load levelling and frequency stabilisation. The current technology, the all-vanadium RFB, has clear advantages but suffers from distinct problems, the low energy density (about 20 times lower than Li-ion batteries) and low specific power density which requires high surface area felt electrodes to mitigate this problem. We propose using complex ions with multiple redox centres (for higher energy density) and high rates of electron transfer (for high power density) and, because of the size of the anions, negligible crossover of ions through the membrane (because of their size of $1+\mathrm{nm}$ diameter). The example shown here is SiW12 for the anolyte and PV14 for the catholyte. The results 
demonstrate that both anions are stable redox systems which demonstrate the predicted properties.

\section{Introduction}

Redox flow batteries (RFBs) are one of the few options to store energy from intermittent renewable energy sources such as wind and solar. ${ }^{1,2}$ While the concept of RFBs itself is very elegant, as it allows for independent scaling of energy and power content, the community has not yet decided on a universal battery chemistry. Currently, there are two schools of thought ${ }^{3-5}$ : The first group advocates dissolved transition metal ions (e.g. $\left.\mathrm{Fe}^{2+} / \mathrm{Fe}^{3+}{ }^{6}, \mathrm{~V}^{2+} / \mathrm{V}^{3+}{ }^{7}\right)$, transition metal oxyanions (e.g. $\mathrm{VO}^{2+} / \mathrm{VO}_{2}{ }^{+7}$ ) or transition metal complexes (e.g. $\left[\mathrm{Fe}(\mathrm{CN})_{6}\right]^{4-}$ $/\left[\mathrm{Fe}(\mathrm{CN})_{6}\right]^{3-8}$ ) as electron carriers (all three will be called metal ions for simplicity), while the second proposes to employ organic redox active materials. ${ }^{4,5,9}$ Both approaches come with their distinct advantages and drawbacks. The champion of the dissolved metal chemistries is the all-vanadium redox flow battery (VRFB). ${ }^{7,10-13}$ Utilizing four oxidation states of vanadium $\left(\mathrm{V}^{2+}, \mathrm{V}^{3+}, \mathrm{VO}^{2+}, \mathrm{VO}_{2}{ }^{+}\right)$this cell chemistry has the advantage that cross-over of species from one half-cell through the separator into the other half-cell does not lead to a chemical contamination and the cell can be rebalanced electrochemically. ${ }^{14}$ The main drawbacks of the VRFB are the sluggish kinetics of the $\mathrm{V}^{2+} / \mathrm{V}^{3+}$ and the $\mathrm{VO}^{2+} / \mathrm{VO}_{2}{ }^{+}$redox reactions which limit the current density and therefore the power density. ${ }^{15}$ While there is debate in the literature about the correct electron rate constant $k_{0}$ for the vanadium reactions and about which half-cell is faster, it is on the order of $k_{0}=10^{-6} \mathrm{~cm} \mathrm{~s}^{-1} \cdot{ }^{15,16}$ Catalysis of the half-cell reactions has been investigated mostly by introducing oxygen containing functional groups onto the graphitic electrodes. ${ }^{17}$ However, we were able to show that these oxygen groups catalyse only the $\mathrm{V}^{2+} / \mathrm{V}^{3+}$ redox reaction and have no influence on or even impede the $\mathrm{VO}^{2+} / \mathrm{VO}_{2}{ }^{+}$redox reaction. ${ }^{18,19}$ Other groups have shown that the positive effects on the $\mathrm{V}^{2+} / \mathrm{V}^{3+}$ half-cell are not permanent because the low potential at which it is operated reduces the oxygen groups, thereby eliminating their catalytic effect. ${ }^{20,21}$ Nevertheless, the VRFB uses the mature RFB chemistry, with large demonstration projects and commercial energy storage power stations built globally; for example the 200 $\mathrm{MW} / 800 \mathrm{MWh}$ power station in Dalian, China, for which the construction contract was signed in October $2016 .^{22}$ Organic redox couples can be low cost and made from abundant elements, and they offer greater variability than metal ion redox couples due to their tuneable structure. ${ }^{5} \mathrm{~A}$ great number of organic redox couples have been presented in recent years, with the capital cost of metal ion RFB chemistries being the main driver for their development. 4,5,23,24 As most studies have been restricted to laboratory cell operation, insights into scale-up with larger cell areas, bigger electrolyte volumes and long-term cycling are currently not available. ${ }^{5}$

Another type of redox electrochemistry that can be employed in RFBs uses polyoxometalates (POMs). POMs form a class of discrete transition metal-oxide nanoclusters. They are prepared from metals, but offer high structural diversity and therefore versatile electrochemistry. ${ }^{25,26}$ We have proposed POMs as electrolyte in RFBs due to four of their properties ${ }^{27}$ :

1. Electrons added to POMs by reduction are often delocalised over several metal atoms, ${ }^{28}$ and this will facilitate fast electron transfer which enables high current densities; ${ }^{29}$

2. POMs are anions and are bigger than solvated transition metals. ${ }^{30,31}$ Therefore POMs should not permeate through cation exchange membranes typically employed in RFBs;

3. Electron transfer by POMs is often coupled to cation or proton transfer. ${ }^{26}$ Therefore, the net charge of the polyoxoanions does not change upon oxidation or reduction. This concept, often found in biological systems, avoids highly charged species and results in increased stability; ${ }^{32}$

4. Some POMs are highly soluble, with the maximum concentration determined by the kind of POM, the electrolyte and also the present counterions. ${ }^{33}$ Coupled with multi-electron transfers per molecule this can lead to high energy densities. ${ }^{34}$

Other studies on POMs as the RFB electrolyte focused on symmetric chemistries, cells in which the same molecule was used as anolyte and catholyte. ${ }^{34-36} \mathrm{~A}$ tri-vanadium substituted Keggin ion $\left(\left[\mathrm{SiV}_{3} \mathrm{~W}^{\mathrm{VI}_{9}} \mathrm{O}_{40}\right]^{7-}\right)$ has been tested in aqueous and non-aqueous solvents. ${ }^{35}$ This system was only demonstrated for a small capacity (4 mAh) at a low POM concentration $(20 \mathrm{mM}) .{ }^{35}$ Much higher concentrations of $0.8 \mathrm{M}$ were reached for an RFB employing $\mathrm{H}_{6}\left[\mathrm{CoW}_{12} \mathrm{O}_{40}\right]$ as anolyte and catholyte. ${ }^{34}$ While $\mathrm{H}_{6}\left[\mathrm{CoW}_{12} \mathrm{O}_{40}\right]$ was well suited as the anolyte (the tungsten-ions transfer four electrons at an average potential of $-0.1 \mathrm{~V}$ vs. SHE) the Cobalt heteroatom transfers only one electron at $1.1 \mathrm{~V}$ vs. SHE. Therefore, to balance the charges in the two tanks the catholyte volume had to be four times larger than the anolyte volume. A capacity of $13.4 \mathrm{Ah} \mathrm{L}^{-1}$ was demonstrated for the anolyte, while the 
catholyte exhibited only 3.3 $\mathrm{Ah} \mathrm{L}^{-1} .{ }^{34}$ Another symmetric POM RFB was presented by VanGelder et al. who employed a series of Lindqvist polyoxovanadate-alkoxide clusters as electroactive species in acetonitrile. ${ }^{36}$

Because it is difficult to prepare a substituted POM that transfers more than three electrons at potentials suitable for a catholyte, we propose an asymmetric POM chemistry for RFBs. In POMs, a trend was observed that with increasing electronegativity $\chi$ of the polyatom the redox potential decreases ${ }^{37}$, and Tungsten $(\chi=2.36)$ is the most electronegative metal that can be used as polyatom in POMs, and so $\left[\mathrm{SiW}_{12} \mathrm{O}_{40}\right]^{4-}\left(\mathrm{SiW}_{12}\right)$ was used as anolyte. A ball-and-stick representation of the anion is shown in Fig. 1 b. Because of the low electronegativity of vanadium $(\chi=1.63)$, a polyoxovanadate anion was chosen as catholyte species: $\left[\mathrm{PV}_{14} \mathrm{O}_{42}\right]^{9-}\left(\mathbf{P V}_{\mathbf{1 4}}\right)$, shown in Fig. $1 d{ }^{38} \mathrm{The}^{3}$ POMs have a similar structure (Keggin structure), with the difference that $\mathbf{P V}_{\mathbf{1 4}}$ has two additional metal-oxygen caps. Besides the four hypotheses mentioned above, we investigated the electrochemistry of $\mathbf{S i W}_{\mathbf{1 2}}$ and $\mathbf{P V}_{\mathbf{1 4}}$ in detail, assessed the long term stability of $\mathbf{P V}_{\mathbf{1 4}}$ and followed its reduction by in-situ ${ }^{51} \mathrm{~V}$ NMR to check that no other species possibly form during the electron transfer. With ${ }^{51} \mathrm{~V}$ NMR we were also able to show that $\mathbf{P V}_{\mathbf{1 4}}$ spontaneously reassembles after decomposition resulting from exposure to a solution with a $\mathrm{pH}$ outside its stability window. In flow battery studies the $\mathbf{S i}_{\mathbf{1 2}}-\mathbf{P V}_{\mathbf{1 4}}$ chemistry was tested for 14 days and ${ }^{51} \mathrm{~V}$ NMR was employed to confirm that the catholyte remained stable during cycling.

\section{Results}

Electrochemical investigation of the polyoxometalates $\mathrm{SiW}_{12}$ and $\mathrm{PV}_{14}$
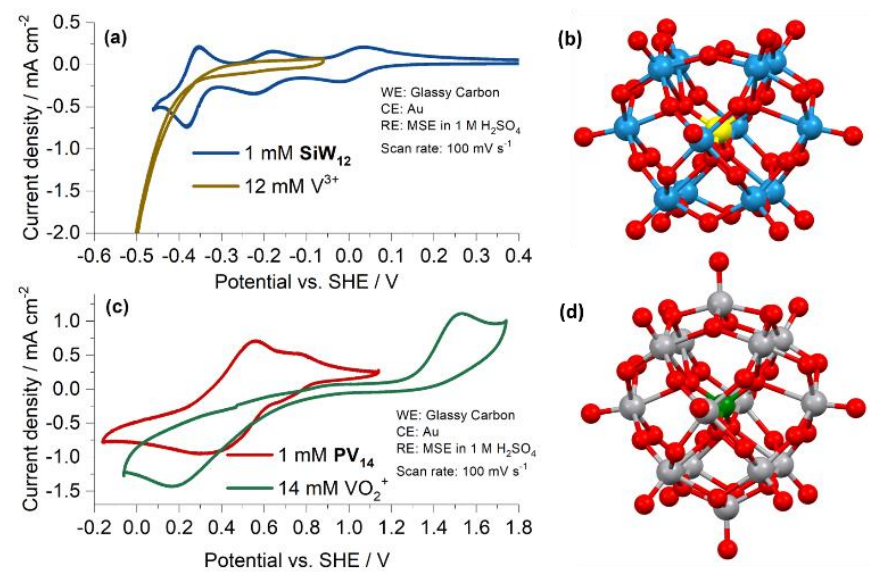

Fig. 1 Cyclic Voltammograms of polyoxometalates and single vanadium ions $\mathrm{V}^{3+}, \mathrm{VO}_{2}{ }^{+}$. (a) Comparison of $1 \mathrm{mM} \mathrm{SiW}_{12}$ and $12 \mathrm{mM} \mathrm{V}^{3+}$ in $1 \mathrm{M} \mathrm{H}_{2} \mathrm{SO}_{4}$ These are the anolyte species of the presented all-POM RFB and the VRFB. (b) Ball-and-stick representation of $\mathbf{S i W}_{\mathbf{1 2}}$. (c) Comparison of 1 mM $\mathbf{P V}_{\mathbf{1 4}}$

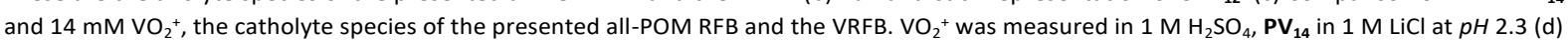
Ball-and-stick representation of $\mathbf{P V}_{\mathbf{1 4}}$. Color code: Silicon - yellow; phosphorus - green; tungsten - blue; vanadium - silver; oxygen - red.

Fig 1a compares a cyclic voltammogram (CV) of $1 \mathrm{mM} \mathrm{SiW}_{\mathbf{1 2}}$ with a CV of $12 \mathrm{mM} \mathrm{V}^{3+}$ in $1 \mathrm{M} \mathrm{H}_{2} \mathrm{SO}_{4}$. The electrodes are glassy carbon (GC) discs used after polishing. The CV of $\mathbf{S i W}_{\mathbf{1 2}}$ exhibits the typical pattern of two one-electron redox reactions followed by one two-electron redox reaction which has been described in the literature. ${ }^{39-41}$ Determined equilibrium potentials $U_{0}\left(\mathrm{SiW}_{12}\right)$, peak potential separations $\Delta U$ and number of transferred electrons $n$ for the three redox reactions of $\mathbf{S i W}_{\mathbf{1 2}}$ at 100 $\mathrm{mV} \mathrm{s}^{-1}$ are given in table 1 : 


\begin{tabular}{|l|l|l|l|}
\hline Redox reaction & $\mathrm{n}$ & $\begin{array}{l}U_{0}\left(\mathrm{SiW}_{12}\right) / \mathrm{V} \\
\text { vs. SHE }\end{array}$ & $\Delta U / \mathrm{mV}$ \\
\hline $\mathbf{S i W}_{\mathbf{1 2}} / \mathbf{S i W}_{\mathbf{1 2}}{ }^{-}$ & 1 & 0.01 & 57 \\
\hline $\mathbf{S i W}_{\mathbf{1 2}}{ }^{-} / \mathbf{S i W}_{\mathbf{1 2}}{ }^{\mathbf{}}$ & 1 & -0.21 & 56 \\
\hline $\mathbf{S i W}_{\mathbf{1 2}}{ }^{\mathbf{2}} / \mathbf{S i W}_{\mathbf{1 2}}{ }^{\mathbf{4}}$ & 2 & -0.37 & 29 \\
\hline
\end{tabular}

Table 1: Parameters of the $\mathbf{S i W}_{\mathbf{1 2}}$ redox reactions determined from the CV shown in Fig. $1 \mathrm{a}$ at $100 \mathrm{mV} \mathrm{s}^{-1}$.

The determined values for $\Delta U$ are small, in fact they are close to the theoretical minimum for a one $(59 \mathrm{mV})$ or a two $\left(29.5 \mathrm{mV}\right.$ ) electron redox reaction. The redox behaviour of $\mathbf{S i W}_{\mathbf{1 2}}$ is well investigated and the 1-1-2 electron redox pattern has been reported by many authors ${ }^{39-41}$. In this study, we have restricted the reduction of $\mathbf{S i W}_{\mathbf{1 2}}$ to the first two electron transfers because at potentials in the vicinity of the third redox wave the POM irreversibly modifies the electrode which leads to its decomposition and catalysis of the hydrogen evolution reaction (HER). ${ }^{42}$ The $\mathrm{V}^{2+} / \mathrm{V}^{3+}$ redox reaction is a sluggish reaction and exhibits significant current only on oxidised carbon materials, on the polished glassy carbon electrode used here the current is negligeable. ${ }^{18,20,43,44}$ In Fig. S4 of the ESI a comparison of the $\mathrm{CVs}$ of $\mathrm{V}^{2+} / \mathrm{V}^{3+}$ on a polished and oxidised electrode is shown. This has consequences for the VRFB in which the evolution of hydrogen decreases the coulombic efficiency. ${ }^{45}$

With standard potentials of $U_{0,1}\left(\mathrm{SiW}_{12}\right)=0.01 \mathrm{~V}$ vs. SHE and $U_{0,2}\left(\mathrm{SiW}_{12}\right)=-0.21 \mathrm{~V} \mathrm{vs}$. SHE, the first two redox reactions of the POM are positive of the measured standard potential of the $\mathrm{V}^{2+} / \mathrm{V}^{3+}$ redox reaction $U_{0}\left(\mathrm{~V}^{2+} / \mathrm{V}^{3+}\right)=$ $-0.29 \mathrm{~V}$ vs. SHE. However, the peak separations and the comparable current density, despite a twelve-fold higher concentration for the $\mathrm{V}^{3+}$, suggest that the electron transfer for $\mathbf{S i W}_{\mathbf{1 2}}$ is much faster than for $\mathrm{V}^{2+} / \mathrm{V}^{3+}$. For the latter the literature gives values on $\mathrm{GC}$ of $k_{0}^{\mathrm{V}^{2+} / \mathrm{V}^{3+}}=10^{-6} \mathrm{~cm} \mathrm{~s}^{-1} \cdot{ }^{15}$ Electrochemical impedance spectroscopy (EIS) (see ESI, Fig. S3 and Table S1) shows that the transfer of the first redox wave, $\mathbf{S i W}_{\mathbf{1 2}} / \mathrm{SiW}_{\mathbf{1 2}}$, proceeds at a rate of $k_{0}=1.110^{-2} \mathrm{~cm} \mathrm{~s}^{-1}$ and for the second redox wave, $\operatorname{SiW}_{12}{ }^{-} / \mathrm{SiW}_{12}{ }^{2-}, k_{0}=1.810^{-2} \mathrm{~cm} \mathrm{~s}^{-1}$ was measured. Therefore, the kinetics of $\mathbf{S i W}_{\mathbf{1 2}}$ are significantly more facile than those of $\mathrm{V}^{2+} / \mathrm{V}^{3+}$. The diffusion coefficient of $\mathbf{S i W}_{\mathbf{1 2}}$ was also determined by EIS to be approximately $D \approx 10^{-6} \mathrm{~cm}^{2} \mathrm{~s}^{-1}$. Inserting this value into the Stokes-Einstein equation, $D=$ $k_{B} T / 6 \pi \eta r$, with $k_{B}$ Boltzmann's constant, $T$ absolute temperature, $\eta$ dynamic viscosity ${ }^{46}$ and $r$ hydrodynamic radius of spherical particle, gives a value of $r=2 \mathrm{~nm}$ for $\mathbf{S i W}_{\mathbf{1 2}}$. This is larger than the crystallographic radius $(r \approx$ $0.5 \mathrm{~nm}$ ), but this makes sense as the hydration shell of the charged molecule has to be considered, too. ${ }^{41}$

Fig $1 c$ compares a CV of $1 \mathrm{mM} \mathrm{PV}_{\mathbf{1 4}}$ recorded in $1 \mathrm{M} \mathrm{LiCl}$ at $p H 2.3$ with a CV of $14 \mathrm{mM} \mathrm{VO}_{2}{ }^{+}$in $1 \mathrm{M} \mathrm{H}_{2} \mathrm{SO}_{4}$. Because $\mathbf{P V}_{\mathbf{1 4}}$ is less investigated than $\mathbf{S i W}_{\mathbf{1 2}}$, we will present a more detailed study here. The $\mathbf{P V}_{\mathbf{1 4}}$ redox waves are multielectron transitions, the overlap of many redox reactions makes it difficult to determine exact standard potentials and peak separations. Comparison with $14 \mathrm{mM} \mathrm{VO}_{2}{ }^{+}$shows that $1 \mathrm{mM} \mathbf{P V}_{\mathbf{1 4}}$ reaches similar peak current densities.

For the $\mathrm{VO}^{2+} / \mathrm{VO}_{2}{ }^{+}$redox reaction with standard potential $U_{0}\left(\mathrm{VO}^{2+} / \mathrm{VO}_{2}^{+}\right)=1.0 \mathrm{~V} \mathrm{vs}$. $\mathrm{SHE}^{13}$ the peak separation is $1.37 \mathrm{~V}$ at $100 \mathrm{mV} \mathrm{s}^{-1}$, which is typical for very sluggish redox reactions $\left(k_{0}^{\mathrm{VO}^{2+} / \mathrm{VO}_{2}^{+}}=10^{-6} \mathrm{~cm} \mathrm{~s}^{-147-50}\right)$. Fig. 2a shows $5 \mathrm{CVs}$ of $20 \mathrm{mM} \mathrm{PV}_{14}$ at scan rates from $10 \mathrm{mV} \mathrm{s}^{-1}$ to $250 \mathrm{mV} \mathrm{s}^{-1}$. Both the oxidation wave and the reduction wave consist of (at least) two individual peaks, labelled Ox. 1, Ox. 2, Red. 1 and Red. 2 in Fig. 2a. The peaks Ox. 2 and Red. 2 are the most pronounced for all scan rates, their arithmetic mean gives an approximate standard potential $U_{0}\left(\mathrm{PV}_{14}\right)=0.60 \mathrm{~V}$ vs. SHE. The peak potential positions shift only minimally with scan rate, Ox. 2 shifts $13 \mathrm{mV}$ higher from $0.01 \mathrm{~V} \mathrm{~s}^{-1}$ to $0.25 \mathrm{~V} \mathrm{~s}^{-1}$, during the same change in scan rate the potential position of Red. 2 decreases by $18 \mathrm{mV} \mathrm{s}^{-1}$. However, because it is unknown how many electrons are transferred during each peak a kinetic assessment is difficult.

In order to determine the number of electrons $n$ transferred in the redox waves the peak current densities of Ox. 2 and Red. 2 are plotted over the square-root of the scan rate in Fig. $2 b$. The data points for oxidation reaction and reduction reaction are on a straight line for smaller scan rates, but for $0.1 \mathrm{~V} \mathrm{~s}^{-1}$ and $0.25 \mathrm{~V} \mathrm{~s}^{-1}$ they fall below those lines. This indicates a limitation in the rate of electron transfer, like by a slower preceding chemical reaction. 

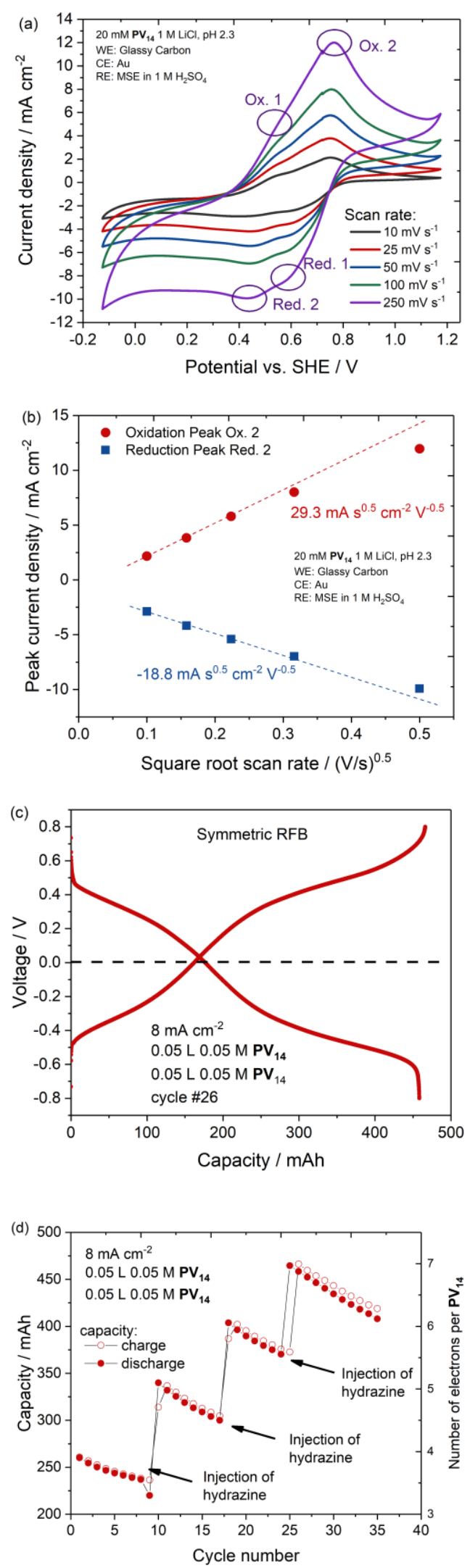

Fig. 2 Electrochemical investigation of $\mathbf{P V}_{\mathbf{1 4}}$. (a) Cyclic Voltammograms of $20 \mathrm{mM} \mathbf{P V}_{\mathbf{1 4}}$ with various scan rates. Observed peaks are labelled. (b) Peak current density vs. square-root of scan rate for peaks Ox. 2 and Red. 2. (c) A charge-discharge curve for a symmetric flow cell with $\mathbf{P V} \mathbf{V}_{\mathbf{1 4}}$ (d) Discharge capacity over cycle number for the symmetric flow cell. 
The determined slopes allow us to determine $n$ with the Randles-Sevcik equation, if the diffusion coefficient is known. Because $\mathbf{S i W}_{\mathbf{1 2}}$ and $\mathbf{P V}_{\mathbf{1 4}}$ are of similar size, we insert the diffusion coefficient of $\mathbf{S i W _ { \mathbf { 1 2 } }}$ determined in Fig. S3 into the Randles-Sevcik equation. The calculation yields that during the oxidation $n^{\mathrm{ox}}=5.5$ electrons are transferred, during the reduction $n^{\text {red }}=3.6$ in the investigated peaks. The imbalance between $n^{\text {red }}$ and $n^{\text {ox }}$ can be explained by the larger size of Red. 1 than Ox. 1 as additional electrons are transferred. However, $n^{\text {red }}$ and $n^{\text {ox }}$ are only rough estimates, the baseline of the preceding peaks (Ox. 1 and Red. 1) are not been taken into account, the inserted value for $D$ most likely comes with a large error, and non-integer values for $n$ do not make sense. However, it is clear from the analysis that indeed multiple electrons are transferred during the redox waves in shown Fig. 2a.

To confirm that multiple electrons can be transferred per $\mathbf{P V}_{\mathbf{1 4}}$ polyoxoanion, a symmetrical flow cell was set up. Both tanks of the cell, anolyte and catholyte, were $0.05 \mathbf{M ~ P V}_{\mathbf{1 4}}$ solution. Hydrazine was added to one tank to reduce the $\mathbf{P V}_{\mathbf{1 4}}$ in it. The electrons generated by this chemical reduction are then transferred from one tank to the other during the charge and discharge of the battery. Because the amount of $\mathbf{P V}_{\mathbf{1 4}}$ is known, the reached capacity $Q$ is a direct measure for the number of electrons transferred per molecule $n$ :

$$
Q=n V c
$$

With $\mathrm{V}$ volume of the tanks and $\mathrm{c} \mathbf{P V}_{\mathbf{1 4}}$ concentration. One cycle of the symmetric battery is shown in Fig. 2c. As can be seen, the charge and discharge curves (at $8 \mathrm{~mA} \mathrm{~cm}{ }^{-2} / 200 \mathrm{~mA}$ ) are symmetrical around zero cell voltage, as expected for a symmetrical flow cell. Multiple additions of hydrazine increased the capacity with each injection. The maximum number of electrons transferred was $n=7$, higher numbers were not tested. This result confirmed the findings of Fig. $2 a$ and Fig. $2 b$, that the redox reactions of $\mathbf{P V}_{\mathbf{1 4}}$ are multi-electron. The capacity of the symmetric flow battery faded quickly, at approximately $5 \mathrm{mAh}$ per cycle, which is attributed to reoxidation of reduced $\mathbf{P V}_{\mathbf{1 4}}$ species, as the tanks were not purged with nitrogen during the experiment.

One aspect that arises from the use of $\mathbf{P V}_{\mathbf{1 4}}$ in the catholyte of an RFB is that the electron exchange is coupled to a proton transfer. In Fig. S5 we show the evolution of the $\mathbf{p H}$ value for an electrolyte in which $\mathbf{P V}_{\mathbf{1 4}}$ is reduced (for experimental details see the ESI). Upon reduction $\mathbf{P V}_{\mathbf{1 4}}$ takes up electrons and protons. Thus for a solution with fixed volume the $\mathrm{pH}$ rises from 2.3 to 3.0 in a $10 \mathrm{mM} \mathrm{PV}_{\mathbf{1 4}}$ electrolyte and to $\mathrm{pH} 5$ in a $30 \mathrm{mM} \mathbf{P V}_{\mathbf{1 4}}$ electrolyte upon reduction by two electrons. Subsequent oxidation of $\mathbf{P V}_{\mathbf{1 4}}$ returns the $p H$ to its initial value. We assume that this experiment worked without destroying the $\mathbf{P V}_{\mathbf{1 4}}$ because the POMs served as buffer solution. This is suggested by the titration curve recorded while synthesising $\mathbf{P V}_{\mathbf{1 4}}$ by addition of conc. $\mathrm{HCl}$ (compare ESI, Fig. S1). A solution with $\mathrm{pH} 2$, which corresponds to a hydronium ion concentration of $c_{\mathrm{H}_{3} \mathrm{O}^{+}}=0.02 \mathrm{M}$, cannot supply the required electrons to allow $0.03 \mathbf{M ~ P V}_{\mathbf{1 4}}$ to take up 2 protons per molecule. Therefore, $\mathbf{P V}_{\mathbf{1 4}}$ must release protons with increasing $\mathrm{pH}$, a phenomenon that counteracts the consumption of protons during the proton coupled electron transfer (PCET). This buffer effect is in line with research from Selling et al. who found that there are multiple $\left[\mathrm{H}_{\mathrm{x}} \mathrm{PV}_{14} \mathrm{O}_{42}\right]^{(9-\mathrm{x})}$ - species with $\mathrm{x}=1-6$ in a $p H$ range from $1.5<p H 6.5$, each species with its own $\mathrm{pK}_{\mathrm{a}}$ value. ${ }^{51}$

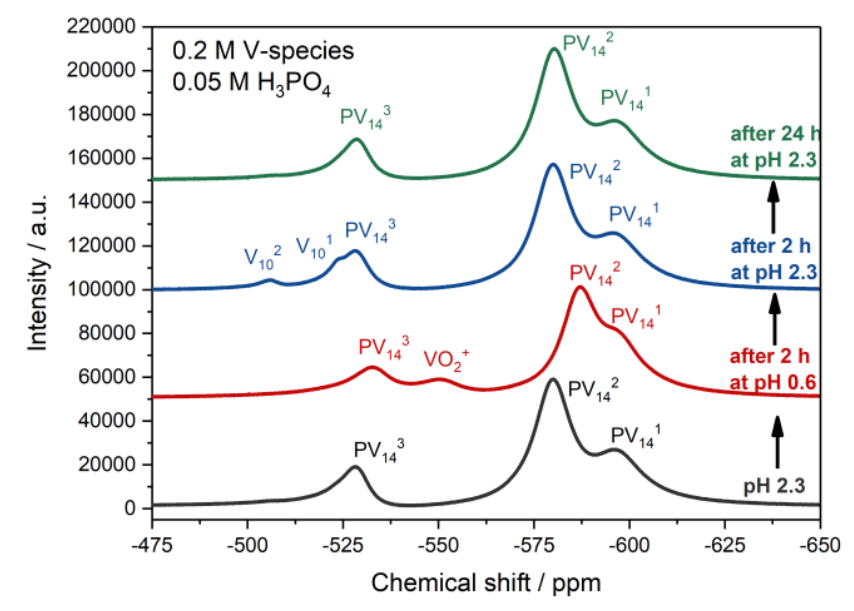

Stability of the polyoxometalates SiW 12 and $\mathrm{PV}_{14}$

Fig. 3 Evolution of ${ }^{51} \mathrm{~V}$ NMR spectra of $0.2 \mathrm{M}$ vanadium species in $0.05 \mathrm{M} \mathrm{H}_{3} \mathrm{PO}_{4}$ initially at $p H 2.3$.

Stability of all redox species used is one of the main criteria for suitability as RFB electrolyte. As POMs are fairly complicated molecules, it is imperative to test whether they remain stable or possibly decompose. $\mathbf{S i W}_{\mathbf{1 2}}$ is known to be a stable Keggin ion which exists in very acidic media and starts to decompose at $\mathrm{pH} 4.5 .^{52,53}$ The decomposition mechanism of $\mathbf{S i W}_{\mathbf{1 2}}$ to $\left[\mathrm{WO}_{4}\right]^{2-}$ and $\left[\mathrm{SiO}_{4}\right]^{4-}$ proceeds via the intermediates $\left[\mathrm{SiW}_{11} \mathrm{O}_{39}\right]^{8-}$ and $\left[\mathrm{SiW}_{9} \mathrm{O}_{34}\right]^{10-} .{ }^{14}$ Because the literature studies investigated the stability of $\mathbf{S i W}_{\mathbf{1 2}}$ at low concentrations $c$ (e.g. $c=$ $610^{-4} \mathrm{M}$ in ref ${ }^{52}$ ) we looked at $p H$ stability at a concentration more suitable for RFBs, $c=0.1 \mathrm{M}$. The voltammetric response of $\left[\mathrm{SiW}_{11} \mathrm{O}_{39}\right]^{8-}$ and $\left[\mathrm{SiW}_{9} \mathrm{O}_{34}\right]^{10-}$ is clearly distinct from that of $\mathrm{SiW}_{12}{ }^{26}$, therefore $\mathrm{CVs}$ were employed as analytical tools to assess stability. We determined that after 24 hours in electrolytes with $1 \leq p H \leq 6 \operatorname{SiW}_{12}$ at $c=$ $0.1 \mathrm{M}$ was undamaged (see Fig. S2). 
Selling et al. showed by ${ }^{51} \mathrm{~V} N M R$ that $\mathbf{P V}_{\mathbf{1 4}}$ in solution is in equilibrium with free vanadium $\left(\mathrm{VO}_{2}{ }^{+}\right)$and decavanadate $\left(\left[\mathrm{V}_{10} \mathrm{O}_{28}\right]^{6-}\right){ }^{51} \mathbf{P V}_{\mathbf{1 4}}$ is the dominant vanadium species at around $p H$ 2.3, more acidic conditions favour $\mathrm{VO}_{2}{ }^{+}$, whereas higher $\mathrm{pH}$ values see most vanadium incorporated in $\left[\mathrm{V}_{10} \mathrm{O}_{28}\right]^{6-}$. $\mathbf{P V} \mathbf{1}_{\mathbf{1 4}}$ undergoes PCET and therefore changes the $\mathrm{pH}$ value of its electrolyte when being oxidised or reduced (Fig. S4). This might be expected to shift the $\mathbf{p H}$ of the electrolyte to a value outside of the stability range of $\mathbf{P V}_{\mathbf{1 4}}$. While it was stated that the transformation of $\mathbf{P V}_{\mathbf{1 4}}$ to $\left[\mathrm{V}_{10} \mathrm{O}_{28}\right]^{6-}$ at high $\mathrm{pH}$ and to $\mathrm{VO}_{2}{ }^{+}$at low $\mathrm{pH}$ is a slow process, the exact time dependence was not given. ${ }^{51}$ Therefore, we determined the time-dependence of the transformations as shown in Fig. S6. In electrolytes with $\mathrm{pH}$ from 2.3 to $1.7^{51} \mathrm{~V}$ NMR shows no indication of vanadium species other than $\mathbf{P V}_{\mathbf{1 4}}$ after 78 hours. At $p H 1.317 \%$ of the vanadium is present as free vanadium, and after 78 hours, at $p H 1.1$ this is increased to $51 \%$. Fig. S6b shows that the transformation is not instantaneous but builds up over time. Therefore, in an RFB electrolyte a $\mathrm{pH}$ value of 1.7 can be tolerated permanently, and even lower values are permissible for short periods of time. This dynamic equilibrium of vanadium species, first described by Selling et al., endows $\mathbf{P V}_{\mathbf{1 4}} \mathbf{W i t h}$ self-repairing properties. ${ }^{51}$ This is demonstrated in Fig. 3 which shows ${ }^{51} \mathrm{~V}$ NMR spectra of various vanadium species. Initially, at $p H 2.3$ (grey spectrum), three peaks are present. These can be attributed to the three vanadium positions in $\mathrm{PV}_{14} ;{ }^{51} \mathrm{PV}_{14}{ }^{3}$ stems from the two vanadium atoms in the cap, $\mathrm{PV}_{14}{ }^{1}$ from the 4 vanadium atoms in the plane of the phosphorous ion in the centre, and $\mathrm{PV}_{14}{ }^{2}$ from the remaining eight. Reducing the $\mathrm{pH}$ to 0.6 with $\mathrm{HCl}$ (red curve) leads to a shift of the vanadium species equilibrium towards free vanadium, its peak emerges at $-550 \mathrm{ppm}$ in the spectrum. At $\mathrm{pH} 0.6 \mathrm{PV}_{14}{ }^{1}, \mathrm{PV}_{14}{ }^{2}$ and $\mathrm{PV}_{14}{ }^{3}$ are located at more negative chemical shifts than at $p H 2.3$, an effect that has been reported before. ${ }^{51}$ Successive increase of $p H$ to 2.3 showed that the $\mathrm{VO}_{2}{ }^{+}$peak had vanished after two hours, however peaks for $\left[\mathrm{V}_{10} \mathrm{O}_{28}\right]^{6-}$ have appeared (blue curve). Remeasuring this solution after 24 hours yields a spectrum that contains only $\mathbf{P V}_{\mathbf{1 4}}$ (green curve), the molecule has reassembled. It is plausible that the formation of $\mathbf{P V}_{\mathbf{1 4}}$ from $\mathrm{VO}_{2}{ }^{+}$proceeds via $\left[\mathrm{V}_{10} \mathrm{O}_{28}\right]^{6-}$ as intermediate, because a few synthesis protocols for $\mathbf{P V}_{\mathbf{1 4}}$ start with decavanadate. ${ }^{55,56}$

\section{In-situ ${ }^{51} \mathrm{~V}$ NMR of $\mathrm{PV}_{14}$}

Because there is a fluent transition between $\mathrm{VO}_{2}{ }^{+},\left[\mathrm{V}_{10} \mathrm{O}_{28}\right]^{6-}$ and $\mathbf{P V}_{14}$, we performed in-situ ${ }^{51} \mathrm{~V}$ NMR to detect whether the $\mathbf{P V}_{\mathbf{1 4}}$ molecule is stable upon reduction (and therefore acts as the actual electron carrier in the RFB). Alternatively, $\mathbf{P V}_{\mathbf{1 4}}$ could disintegrate upon reduction, potentially due to a local change in $p H$, into a $\mathrm{V}(\mathrm{IV})$ containing species and reassemble when re-oxidised. Using in-situ ${ }^{51} \mathrm{~V} N \mathrm{NR}$, the chemical composition of $50 \mathrm{mM}$ $\mathbf{P V}_{14}$ was monitored during reduction and oxidation in the NMR spectrometer (Fig 4a). Fig. 4c shows a schematic of the in-situ NMR cell. A carbon felt (GFD, SGL carbon) working electrode was contacted with a partly insulated gold wire $(0.2 \mathrm{~mm}$ diameter), another gold wire served as counter- and reference electrode ( $0.5 \mathrm{~mm}$ diameter). The carbon felt assumed a cylindrical shape of diameter $4 \mathrm{~mm}$ and height $25 \mathrm{~mm}$. We estimate that the volume of electrolyte contained in the porous electrode was $(0.30 \pm 0.05) \mathrm{mL}$.

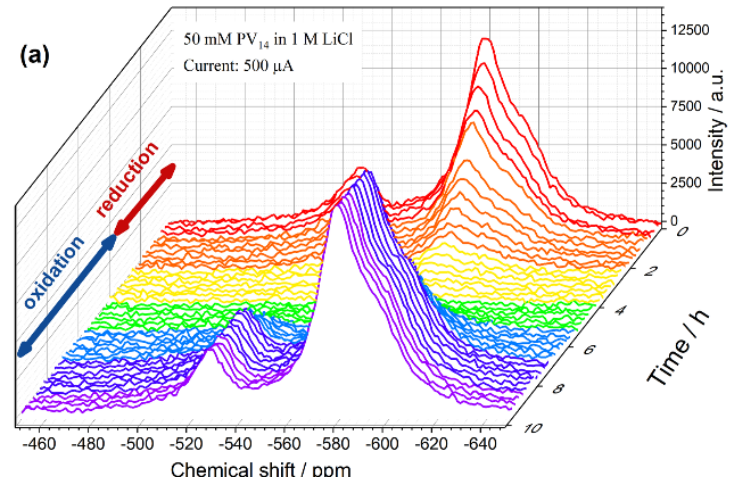

Chemical shift / ppm

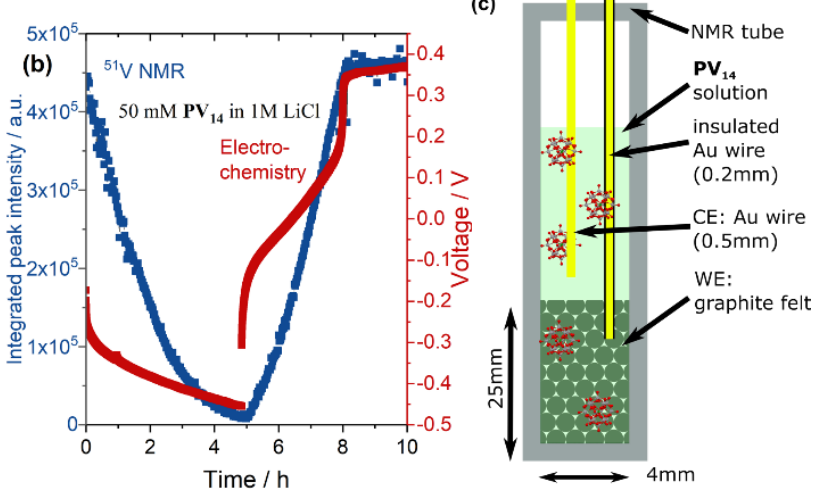

Fig. 4 (a) ${ }^{51} \mathrm{~V}$ NMR spectra recorded in an NMR tube during an electrochemical experiment. In the graph, time proceeds from the back (red curve) to the front of the plane (blue curve). The time during which a reducing or an oxidizing current were applied are marked. (b) Integrated intensity of all three vanadium peaks (left, blue) and measured voltage (red, right). (c) Schematic of the insitu NMR cell.

Therefore, with a concentration of $50 \mathrm{mM}$, a charge of $Q^{\text {theo }}=(1.4 \pm 0.2) C(\equiv(0.40 \pm 0.07) \mathrm{mAh})$ has to be transferred to reduce the $\mathbf{P V}_{\mathbf{1 4}}$ within the electrode by one electron. Fig. 4a shows spectra recorded during the reduction and oxidation of $\mathbf{P V}_{\mathbf{1 4}}$ inside the in-situ NMR cell. The first plot is the red spectrum at $t=0 \mathrm{~h}$, then every tenth recorded spectrum is shown until $t=10 \mathrm{~h}(36000 \mathrm{~s}$, blue line). During the reduction phase with a current of $500 \mu \mathrm{A}$ the three peaks typically observed for $\mathbf{P V}_{\mathbf{1 4}}$ decreased until their integrated intensity was close to zero after $t=5 \mathrm{~h}(18000 \mathrm{~s}$, as shown in Fig. 4b, blue data). The charge transferred during this time 
was $Q=-2.4 \mathrm{mAh}$ ( $\equiv 6 \pm 1$ electrons per $\mathbf{P V}_{\mathbf{1 4}}$ ). At this point a positive current of $500 \mu \mathrm{A}$ was applied and the peaks began to reappear until at $t=8.3 \mathrm{~h}$ the integrated peak intensities reached a plateau at their original values prior to the reduction. During this interval $Q=1.6 \mathrm{mAh}\left(\equiv 4 \pm 0.7\right.$ electrons per $\mathbf{P V}_{\mathbf{1 4}}$ ) were transferred. The interpretation is as follows:

- Peak intensity decreases upon reduction because diamagnetic $\mathrm{V}(\mathrm{V})$ is transformed to paramagnetic $\mathrm{V}(\mathrm{IV}) .{ }^{57}$ The fact that all three peaks of the $\mathbf{P V}_{\mathbf{1 4}}$ lose intensity simultaneously indicates that the added electrons are delocalized, therefore influencing all three vanadium positions;

- As estimated above, the charge transferred per $\mathbf{P V}_{\mathbf{1 4}}$ polyoxoanion corresponds to the addition of 6 electrons when its intensity in the ${ }^{51} \mathrm{~V}$ NMR spectrum vanished entirely. Re-oxidation was completed after removing 4 electrons from each polyoxoanion. The absence of a separator in the NMR tube is a likely reason for this imbalance. During reduction, reduced species diffuse out of the working electrode volume into the supernatant region, and these are replaced by fully oxidised $\mathbf{P V}_{\mathbf{1 4}}$. These molecules can also be reduced so that the number of electrons added during reduction is likely higher than the number which would be needed without diffusion. Similarly, in the oxidation phase, less $\mathbf{P V}_{\mathbf{1 4}}$ can be re-oxidised, because some of the reduced species is able to diffuse away from the working electrode. Therefore less electrons are removed from the polyanions during the oxidation than would be possible without diffusion.

The conclusion is that $\mathbf{P} \mathbf{V}_{\mathbf{1 4}}$ can be reversibly reduced and oxidised. Taking the error from diffusion into account, we estimate that the ${ }^{51} \mathrm{~V}$ NMR signal disappears after approximately five $((6+4) / 2=5)$ electrons have been added to the 14 vanadium ions of the POM.

\section{Cross-over and flow battery studies}

One prerequisite for an asymmetric RFB is that the redox shuttles do not penetrate the membrane. We compared the crossover of $\mathrm{Fe}^{2+}$, as archetype for a small transition metal ion, with that of $\mathbf{S i W}_{\mathbf{1 2}}$ for two commercial membranes, Nafion N117 (thickness $183 \mu \mathrm{m}$ ) and Fumatech's FUMASEP F-1040 (thickness $40 \mu \mathrm{m}$ ). As the direct comparison of $100 \mathrm{mM} \mathrm{Fe}^{2+}$ and $100 \mathrm{mM} \mathrm{SiW}_{12}$ (Fig. S7) showed, the small cation $\mathrm{Fe}^{2+}$ easily crosses both tested membranes. The half-cell that initially was devoid of $\mathrm{Fe}^{2+}$ and was separated by the membrane from a half-cell with $100 \mathrm{mM} \mathrm{Fe}^{2+}$, contained half of the initial concentration $(50 \mathrm{mM})$ of $\mathrm{Fe}^{2+}$ after $19 \mathrm{~h}$; the two half-cells had become equilibrated. In the case of the larger anion $\mathbf{S i W}_{\mathbf{1 2}}$, both membranes prevented crossover during the $20 \mathrm{~h}$ of monitoring. The inhibition of crossover for the POM can be explained in two ways. First, size exclusion: From $x-$ ray diffraction in solution it is known that the 12 tungsten atoms of $\mathbf{S i W}_{\mathbf{1 2}}$ form a roughly spherical unit with unit cell of volume $(0.5 \mathrm{~nm})^{3} .^{31}$ With terminal oxygen atoms and hydration shell the diameter of the solvated polyoxoanion is likely to exceed $2 \mathrm{~nm}$, as calculated from the Stokes-Einstein equation from the diffusion coefficient. Conductive channels in Nafion membranes were determined to be of variable size from $1-100 \mathrm{~nm} .^{58,59}$ Narrow points in the channel might therefore restrict the movement of the $\mathbf{S i W}_{\mathbf{1 2}}$ species as they are of similar size. Second, electrostatic repulsion: Both investigated membranes are based on perfluorosulfonic acid ionomers and are therefore cation-conducting membranes. The negatively charged $\mathrm{SO}_{3}{ }^{-}$groups in the membrane might repel the $\left[\mathrm{SiW}_{12} \mathrm{O}_{40}\right]^{4-}$ anion, thus preventing it from crossing the separator.

The flow cell studies were performed in a laboratory flow cell with electrode area $5 \times 5 \mathrm{~cm}^{2}$; a detailed description of the setup is given in the supporting information. The composition of the anolyte was $0.2 \mathrm{M} \mathrm{SiW}_{\mathbf{1 2}}$ in $1 \mathrm{M} \mathrm{LiCl,}$ and the starting $\mathrm{pH}$ was adjusted to 1.6 from 0.6. The catholyte comprised $0.1 \mathrm{M} \mathrm{PV}_{\mathbf{1 4}}$ in $1 \mathrm{M} \mathrm{LiCl}$. Prior to starting the tests, the catholyte was reduced by addition of hydrazine ( $35 \%$ in water) while it was purged with nitrogen. The $\mathrm{pH}$ was then adjusted to 2.0 from 2.6 by addition of aqueous $\mathrm{HCl}(1 \mathrm{M})$. With four electrons per $\mathbf{P V}_{\mathbf{1 4}} \mathrm{molecule}$ added, and each tank containing $60 \mathrm{~mL}$ of electrolyte, the theoretical capacity $Q^{\text {theo }}$ is:

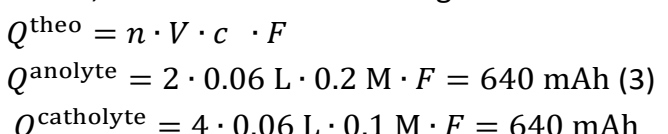

$Q^{\text {catholyte }}=4 \cdot 0.06 \mathrm{~L} \cdot 0.1 \mathrm{M} \cdot F=640 \mathrm{mAh}$

With $n$ number of electrons per molecule, $V$ volume of electrolyte, $F$ Faraday constant and $Q^{\text {anolyte }}, Q^{\text {catholyte }}$ theoretical capacity of anolyte and catholyte.

The area specific resistance (ASR) at high frequencies caused by the ohmic losses in the current collector, the electrodes and the ionic resistance in the membrane was relatively high for an aqueous system, $R_{\text {ohm }}=1.93 \Omega \mathrm{cm}^{2}$ (Nyquist plot in Fig. S8, for comparison see values in ${ }^{60}$ ). Typical charge and discharge curves at three different current densities are shown in Fig. 5a. All curves exhibit two distinct plateaus. These stem from the two redox processes of $\mathbf{S i W}_{\mathbf{1 2}}$ (compare Fig. 1a). For $30 \mathrm{~mA} \mathrm{~cm}^{-2}$ the theoretical capacity of $Q^{\text {theo }}=640 \mathrm{mAh}$ is almost 
reached at discharge $\left(Q^{\exp }=612 \mathrm{mAh}\right)$. Coulombic efficiencies are about $94 \%$ for each cycle, and are slightly higher for higher current densities. The voltage efficiency was $65 \%$ at $30 \mathrm{~mA} \mathrm{~cm}^{-2}$, attributed mainly to the ohmic losses $R_{\mathrm{ohm}}$ and not to the kinetics of the redox couples. This is based on the three electrode measurements which found high $k_{0}$ values for $\operatorname{SiW}_{\mathbf{1 2}}$ in the order of $10^{-2} \mathrm{~cm} \mathrm{~s}^{-1}$ and the Nyquist plot shown in Fig. S8 in which the $R_{C T} \approx$ $0.4 \Omega \mathrm{cm}^{-2}$ when $R_{\text {ohm }}=1.93 \Omega \mathrm{cm}^{2}$.
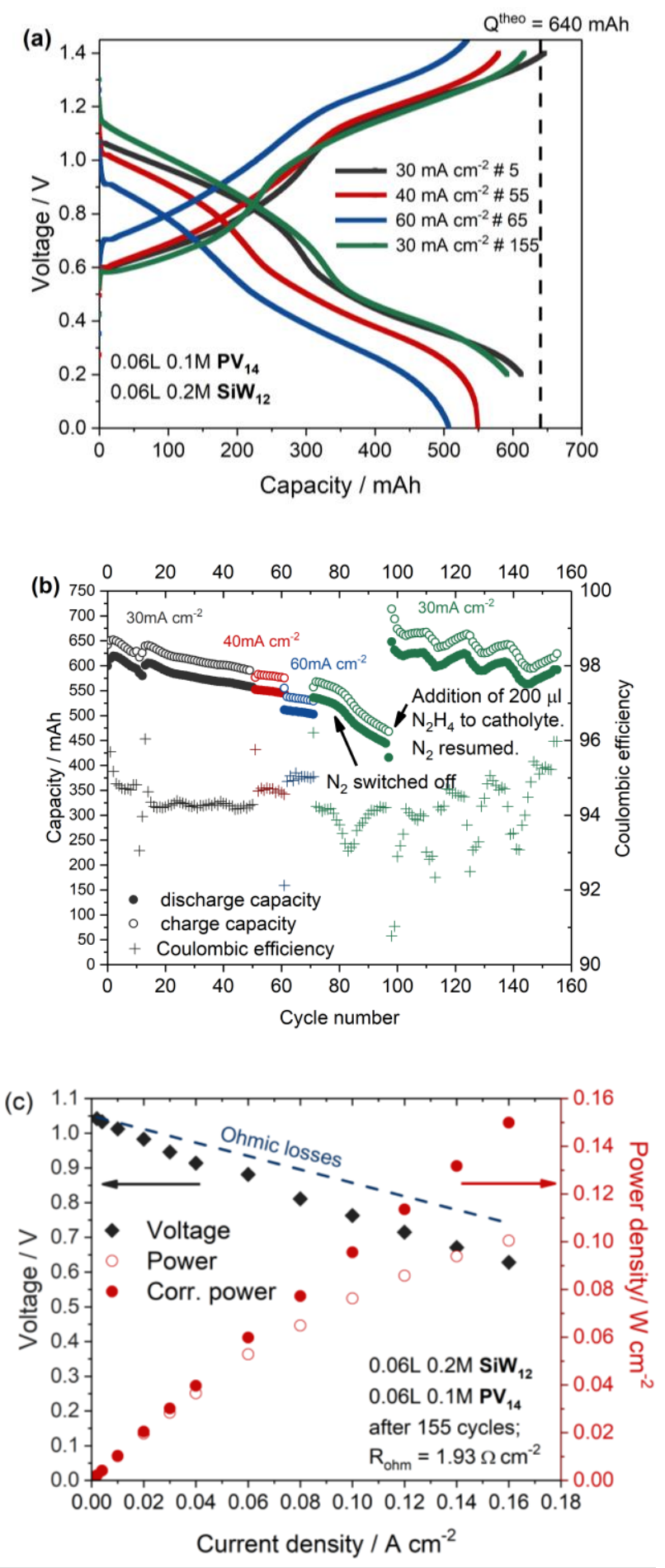

Fig. 5 Flow cell studies on a cell using $0.2 \mathrm{M} \mathrm{SiW}_{12}$ as anolyte and $0.1 \mathrm{M} \mathrm{PV}_{14}$ as catholyte. (a) Typical charge and discharge curves for cycle number 5 at $30 \mathrm{~mA} \mathrm{~cm}^{-2}$ (grey curves), number 55 at $40 \mathrm{~mA} \mathrm{~cm}^{-2}$ (red curves), number 65 at $60 \mathrm{~mA} \mathrm{~cm}^{-2}$ (blue curves) and the last cycle (number 155 ) at 30 $\mathrm{mA} \mathrm{cm}{ }^{-2}$ (green curves). (b) Charge (open circle) and discharge (full circle) capacity for cycles 1-155 with current density indicated. Coulombic efficiencies are given as + symbol (c) Rate test for RFB starting at an open circuit voltage of $1.05 \mathrm{~V}$. The left ordinate gives the discharge voltage, the right ordinate the achieved power density. The voltage drop due to $\mathrm{R}_{\mathrm{ohm}}$ is shown by a broken line. 
This cell was cycled for 14 days, completing 155 charge and discharge cycles. The measured capacities are shown in Fig. 5b. For 50 cycles a current density of $30 \mathrm{~mA} \mathrm{~cm}^{-2}$ was applied (grey markers), followed by ten cycles with 40 $\mathrm{mA} \mathrm{cm}-2$ (red markers) and $60 \mathrm{~mA} \mathrm{~cm}^{-2}$ (blue markers) each. Then the initial current density of $30 \mathrm{~mA} \mathrm{~cm}^{-2}$ (green markers) was reapplied to show that ageing has a negligible effect on the battery. From cycle 20 to cycle 71 the capacity remained relatively stable and decayed with $1 \mathrm{mAh} / c y c l e$. Relative to the highest achieved discharge capacity (619 mAh in cycle 2 ), this equals a capacity decay of $0.16 \%$ per cycle.

Chemical oxidation of reduced $\mathbf{S i W}_{\mathbf{1 2}}$ and reduced $\mathbf{P V}_{\mathbf{1 4}}$ by the oxygen in the atmosphere is the most likely reason for the observed capacity fade. To test this hypothesis, the nitrogen gas purge of the battery containment was stopped at cycle 80, thus permitting the ingress of atmospheric oxygen. From cycle 85 to 97 an increased capacity fade of $3.5 \mathrm{mAh} /$ cycle or $0.56 \%$ / cycle was measured, suggesting that the measured capacity fade is due oxidation by oxygen. ${ }^{61}$ During cycle $98,200 \mu \mathrm{L}$ of hydrazine were added to the catholyte and the nitrogen purging was resumed. This addition of a reducing agent replenished the full capacity of the RFB: Cycle 98 had a discharge capacity of $648 \mathrm{mAh}$, which even exceeded the theoretical capacity. To achieve this, SiW $\mathbf{1 2}$ can partly access its third, two-electron redox reaction, and $\mathbf{P V}_{\mathbf{1 4}}$ can take up more than 4 electrons per anion. Fig. $2 \mathrm{~d}$ shows the charge and discharge of a symmetric RFB that operates with $\mathbf{P V}_{\mathbf{1 4}}$ in both electrolytes. The curves indicate that $\mathbf{P V}_{\mathbf{1 4}}$ can store at least seven electrons. After the hydrazine injection, the cell test was continued to reach a total operation time of 14 days and the capacity fade continued to be $0.16 \%$ / cycle. The capacity oscillates in a day/night cycle, maxima in capacity are separated by 24 hours. It is known from other experiments that the daynight cycle is mainly influenced by temperature changes. The columbic efficiency oscillates with the same periodicity as the capacities.

After the $155^{\text {th }}$ cycle the cell was charged to reach an open circuit voltage of $1.05 \mathrm{~V}$, then the cell was discharged at a certain current rate for $2 \mathrm{mAh}$, and immediately after that charged for $2 \mathrm{mAh}$. This was done for current densities from $2 \mathrm{~mA} \mathrm{~cm}^{-2}$ to $160 \mathrm{~mA} \mathrm{~cm}^{-2}$. The discharge voltage and power at these current densities are shown in Fig. 5c. The maximum achieved power density was $100 \mathrm{~mW} \mathrm{~cm}^{-2}$ at $160 \mathrm{~mA} \mathrm{~cm}^{-2}$. At this current density $73 \%$ of the voltage drop is caused by the ohmic resistance of the cell $\left(R_{\mathrm{ohm}}=1.93 \Omega \mathrm{cm}^{-2}\right)$.

\section{Summary and Conclusions}

In this study an asymmetric all-POM RFB utilising $\mathbf{S i W}_{\mathbf{1 2}}$ as anolyte and $\mathbf{P V}_{\mathbf{1 4}}$ as catholyte is presented. Four hypotheses regarding the suitability of POMs for RFBs were tested.

1. It was shown that electron transfer using $\mathbf{S i W}_{\mathbf{1 2}}$ is fast, an electron transfer on the order of $k_{0}=10^{-2} \mathrm{~cm} \mathrm{~s}^{-1}$ was determined by EIS. This is four orders of magnitude faster than that of the vanadium redox reactions employed in the VRFB. ${ }^{15}$ The simultaneous decrease of the three $\mathbf{P V}_{\mathbf{1 4}}$ peaks in the in-situ ${ }^{51} \mathrm{~V}$ NMR spectrum (Fig. 4) also indicates that added electrons are delocalised. The battery cell achieved a power density of 100 $\mathrm{mW} \mathrm{cm} \mathrm{cm}^{-2}$. The loss in voltage was mostly $(73 \%)$ determined by the ohmic drop and not by charge transfer resistances.

2. Two types of commercial cation exchange membranes (Nafion N117 and FUMASEP F-1040) prevented SiW $_{\mathbf{1 2}}$ from crossing over into an adjacent half-cell (Fig. S7). The smaller $\mathrm{Fe}^{2+}$ cation, which was used for comparison, fully equilibrated across the membranes over 20 hours. After 14 days of RFB operation no vanadium was found in the anolyte by ${ }^{51} \mathrm{~V}$ NMR. Electrostatic repulsion between the $\mathrm{SO}_{3}{ }^{-}$groups of the membranes and the polyoxoanions, and limited transport of the POMs $(1 \mathrm{~nm})$ through membrane channels of comparable size (1$100 \mathrm{~nm}$ ) are likely causes of this prevention of cross-over. ${ }^{31,58,59}$

3. In-situ ${ }^{51} \mathrm{~V}$ NMR showed that $\mathbf{P V}_{\mathbf{1 4}}$ was stable during reduction and oxidation (Fig. 4). Furthermore, the decavanadate also spontaneously reassembled after decomposition in excessively acidic or alkaline solvents when the $\mathrm{pH}$ was restored to 2.3 (Fig. 3).

4. The concentrations examined were $0.1 \mathrm{M}$ for $\mathbf{P V}_{\mathbf{1 4}}$ and $0.2 \mathrm{M}$ for $\mathbf{S i W}_{\mathbf{1 2}}$. With this configuration the RFB had a capacity of $10.7 \mathrm{Ah} \mathrm{L}^{-1}$ and was able to reach this theoretical value reliably with minimal capacity loss $(0.16 \%$ per cycle) which is due to ingress of atmospheric oxygen and not due to instability of the redox shuttles. In VRFBs capacity decays of $2 \% /$ cycle $^{21}$ or $75 \%$ after 50 cycles ${ }^{62}$ have been reported. For the metal-free anthraquinone-bromine RFB an average capacity fade of $0.8 \%$ / cycle was reported. ${ }^{63}$ In addition, the full capacity of the all-POM RFB could be restored by adding a reducing agent to the catholyte.

The above four points illustrate the potential for POMs as designable redox shuttles for flow batteries. There are several possible avenues for improvement: 
Energy density: Two approaches are available to increase the capacity: First, to utilise more electrons per molecule. We were able to show that $\mathbf{P V}_{\mathbf{1 4}}$ can be reduced by as many as seven electrons (Fig. $2 \mathrm{~d}$ ), whereas during battery operation the molecule was reduced by only four electrons. The limit to this needs to be explored. From its CV it is clear that $\mathbf{S i W}_{\mathbf{1 2}}$ can be reduced by four electrons (Fig.1a), two more than are currently utilised in the battery anolyte. However, in order for these two additional electrons to be used the decomposition reaction of $\mathrm{SiW}_{\mathbf{1 2}}$ at low potential must be understood and prevented. ${ }^{39}$ Second, the concentration of the POMs could be increased. For $\mathrm{H}_{4} \mathrm{SiW}_{12} \mathrm{O}_{40}$, the maximum concentration at room temperature we measured was $0.875 \mathrm{M}$.

Power density: The asymmetric POM-RFB reached a power density of $100 \mathrm{~mW} \mathrm{~cm}^{-2}$. For commercial VRB systems power densities of $60-100 \mathrm{~mW} \mathrm{~cm}^{-2}$ are reported. ${ }^{64}$ The ohmic drop causes $73 \%$ of the voltage loss, and this should therefore be improved with the highest priority. When correcting for the ohmic drop a power density of $150 \mathrm{~mW} \mathrm{~cm}^{-2}$ can be achieved (shown in Fig. 5c). Common RFBs are operated in highly acidic conditions, and therefore protons can be used to transfer the charge across the membrane. Since the asymmetric POM-RFB operates in only mildly acidic conditions, it is necessary to use Li cations for charge transport, and we assume that Li transport leads to a lower conductivity than proton transport. Thinner membranes, or separators working on the basis of size exclusion should be tested to take advantage of the large size of the POMs. Higher POM concentrations will also improve the power density.

\section{Acknowledgements}

The authors acknowledge funding from the Siemens AG, Newcastle University and the North East Centre for Energy Materials (NECEM). We thank Prof Walter Klemperer for constructive criticism of the manuscript. FP acknowledges support and funding from the University of Gießen and Erasmus+ for his stay in Newcastle.

\section{Notes and references}

1 C. Ponce de Leon, A. Friasferrer, J. Gonzalezgarcia, D. Szanto and F. Walsh, J. Power Sources, 2006, 160, 716-732.

2 A. Z. Weber, M. M. Mench, J. P. Meyers, P. N. Ross, J. T. Gostick and Q. Liu, J. Appl. Electrochem., 2011, 41, 11371164.

3 J. Winsberg, T. Hagemann, T. Janoschka, M. D. Hager and U. S. Schubert, Angew. Chemie - Int. Ed., 2017, 56, 686711.

4 J. Noack, N. Roznyatovskaya, T. Herr and P. Fischer, Angew. Chemie Int. Ed., 2015, 54, 9776-9809.

5 P. Leung, A. A. Shah, L. Sanz, C. Flox, J. R. Morante, Q. Xu, M. R. Mohamed, C. Ponce de León and F. C. Walsh, J. Power Sources, 2017, 360, 243-283.

6 D. A. Johnson and M. A. Reid, J. Electrochem. Soc., 1985, 132, 1058-1062.

7 M. Skyllas-Kazacos, M. Rychcik, R. G. Robins and A. G. Fane, J. Electrochem. Soc., 1986, 1057-1058.

8 K. Lin, Q. Chen, M. R. Gerhardt, L. Tong, S. B. Kim, L. Eisenach, A. W. Valle, D. Hardee, R. G. Gordon, M. J. Aziz and M. P. Marshak, Science (80-. )., 2015, 349, 1529-32.

9 M. V. Holland-Cunz, F. Cording, J. Friedl and U. Stimming, Front. Energy, 2018, 1-27.

10 B. Sun and M. Skyllas-Kazacos, Electrochim. Acta, 1992, 37, 1253-1260.

11 M. Rychcik and S. Skyllas-Kazacos, J. Power Sources, 1987, 19, 45-54.

12 Q. Huang and Q. Wang, Chempluschem, 2015, 80, 312-322.

S. Corcuera and M. Skyllas-Kazacos, Eur. Chem. Bull., 2012, 1, 511-519.

J. Friedl and U. Stimming, Electrochim. Acta, 2017, 227, 235-245.

H. Fink, J. Friedl and U. Stimming, J. Phys. Chem. C, 2016, 120, 15893-15901.

M. H. Chakrabarti, N. P. Brandon, S. A. Hajimolana, F. Tariq, V. Yufit, M. A. Hashim, M. A. Hussain, C. T. J. Low and P. V. Aravind, J. Power Sources, 2014, 253, 150-166. H. Fink, J. Friedl and U. Stimming, J. Phys. Chem. C, 2016, 120, 15893-15901.

J. Friedl, C. M. Bauer, A. Rinaldi and U. Stimming, Carbon N. Y., 2013, 63, 228-239.

M. A. Miller, A. Bourke, N. Quill, J. S. Wainright, R. P. Lynch, D. N. Buckley and R. F. Savinell, J. Electrochem. Soc., 2016, 163, A2095-A2102. 405. 
Mariusz Kozik, N. Casan-pastor, C. F.Hammer and L. C. W. Baker, J. Am. Chem. Soc., 1988, 110, 7697-7701. E. L. Bominaar, C. Achim, S. a. Borshch, J.-J. Girerd and E. Münck, Inorg. Chem., 1997, 36, 3689-3701. I. K. Song, M. S. Kaba, K. Nomiya, R. G. Finke and M. a. Barteau, J. Mol. Catal. A Chem., 2007, 262, $216-226$. H. A. Levy, P. A. Agron and M. D. Danford, J. Chem. Phys., 1959, 30, 1486-1488.

M. H. V Huynh and T. J. Meyer, Chem. Rev., 2007, 107, 5004-5064. S. Herrmann, J. T. Margraf, T. Clark and C. Streb, Chem. Commun., 2015, 51, 13702-13705.

Y. Liu, S. Lu, H. Wang, C. Yang, X. Su and Y. Xiang, Adv. Energy Mater., 2017, 7, 2-7.

H. D. Pratt, N. S. Hudak, X. Fang and T. M. Anderson, J. Power Sources, 2013, 236, 259-264.

L. E. VanGelder, A. M. Kosswattaarachchi, P. L. Forrestel, T. Cook and E. Matson, Chem. Sci., 2018, 9, 1692-1699. I. K. Song and M. A. Barteau, J. Mol. Catal. A Chem., 2004, 212, 229-236.

C. Streb, in Polyoxometalate-Based Assemblies and Functional Materials, ed. Y.-F. Song, Springer, Oxford, 2017, pp. 31-47.

B. Keita and L. Nadjo, J. Electroanal. Chem. Interfacial Electrochem., 1987, 227, 77-98.

M. Sadakane and E. Steckhan, Chem. Rev., 1998, 98, 219-238.

M. Pope and G. M. Varga, Inorg. Chem., 1966, 5, 3-8.

B. Keita and L. Nadjo, Mater. Chem. Phys., 1989, 22, 77-103.

A. Bourke, N. Quill, R. P. Lynch and D. N. Buckley, ECS Trans., 2014, 61, 15-26.

A. Bourke, R. P. Lynch and D. N. Buckley, ECS Trans., 2013, 53, 59-67.

R. Schweiss, A. Pritzl and C. Meiser, J. Electrochem. Soc., 2016, 163, A2089-A2094.

F. H. Rhodes and C. B. Barbour, Ind. Eng. Chem., 1923, 15, 850-852.

M. V. Holland-Cunz, J. Friedl and U. Stimming, J. Electroanal. Chem., , DOI:10.1016/j.jelechem.2017.10.061.

J. Friedl and U. Stimming, Electrochim. Acta, 2017, 227, 235-245.

M. Gattrell, J. Qian, C. Stewart, P. Graham and B. MacDougall, Electrochim. Acta, 2005, 51, 395-407.

M. Gattrell, J. Park, B. MacDougall, J. Apte, S. McCarthy and C. W. Wu, J. Electrochem. Soc., 2004, 151, A123.

A. Selling, I. Andersson, L. Pettersson, C. M. Schramm, S. L. Downey and J. H. Grate, Inorg. Chem., 1994, 33, 31413150.

A. Jürgensen and J. B. Moffat, Catal. Letters, 1995, 34, 237-244.

P. Souchay, lons minéraux condensés, Masson et Cie, Paris, 1969.

D. L. Kepert and J. H. Kyle, J. Chem. Soc. Dalt. Trans., 1978, 137-141.

V. F. Odyakov, E. G. Zhizhina and R. I. Maksimovskaya, Appl. Catal. A Gen., 2008, 342, 126-130.

V. F. Odyakov, E. G. Zhizhina, Y. A. Rodikova and L. L. Gogin, Eur. J. Inorg. Chem., 2015, 2015, 3618-3631.

X. Lu, W. D. Johnson and J. Hook, Environ. Sci. Technol., 1998, 32, 2257-2263.

E. Aleksandrova, R. Hiesgen, K. A. Friedrich and E. Roduner, Phys. Chem. Chem. Phys., 2007, 9, $2735-2743$.

J. Chou, E. W. McFarland and H. Metiu, J. Phys. Chem. B, 2005, 109, 3252-3256.

R. Darling, K. G. Gallagher, J. A. Kowalski, S. Ha and F. R. Brushett, Energy Environ. Sci., 2014, 3459-3477.

B. Rausch, M. D. Symes, G. Chisholm and L. Cronin, Science (80-. )., 2014, 345, 1326-1330.

I. Derr, A. Fetyan, K. Schutjajew and C. Roth, Electrochim. Acta, 2017, 224, 9-16.

B. Huskinson, M. P. Marshak, C. Suh, S. Er, M. R. Gerhardt, C. J. Galvin, X. Chen, A. Aspuru-Guzik, R. G. Gordon and M. J. Aziz, Nature, 2014, 505, 195-8.

M. R. Mohamed, S. M. Sharkh and F. C. Walsh, in Vehicle Power and Propulsion Conference, 2009. VPPC'09. IEEE, IEEE, 2009, pp. 551-557. 